\title{
Arsenic-Based Anticancer-Combined Therapy: Novel Mechanism Inducing Apoptosis of Cancer Cells
}

\author{
Akinobu Ota, Md Wahiduzzaman and \\ Yoshitaka Hosokawa \\ Additional information is available at the end of the chapter
}

http://dx.doi.org/10.5772/intechopen.74824

\begin{abstract}
Arsenic, known as both a naturally occurring toxic element and a traditionally used drug, has caught a great deal of attention from worldwide people due to its curable anticancer effect in patients with acute promyelocytic leukemia (APL). Among the arsenicals, arsenic trioxide (ATO) has been the most widely used anticancer drug. Since ATO exerts an anticancer effect by mediating apoptosis, numerous studies have made efforts to uncover the molecular mechanisms by which ATO activates and/or mediates the apoptotic signaling pathway in cancer cells. Recent advances in cancer therapeutics have led to a paradigm shift away from the traditional cytotoxic drugs toward the targeting of proteins closely associated with driving the cancer phenotype. Here, we discuss novel current arsenic-based combination therapies to treat cancer in both clinical and experimental settings. We also discuss the novel molecular mechanism underlying apoptosis induced by the combined therapies.
\end{abstract}

Keywords: arsenic trioxide, combination therapy, anticancer effect, apoptosis

\section{Arsenic in cancer treatment}

Arsenic, one of the ancient drugs, is currently used as a therapeutic agent worldwide because of its substantial anticancer activity. Arsenic trioxide (ATO), a trivalent arsenite ( $\left.\mathrm{As}_{\mathrm{III}}\right)$, was initially used for the treatment of chronic myelogenous leukemia (CML) in the nineteenth century [1]. ATO readily induces apoptosis by promoting differentiation of acute promyelocytic leukemia (APL) cells and is thereby utilized as a therapeutic drug in the clinical setting [2]. ATO is currently used to treat patients with APL and recurrent/relapsed multiple myeloma (MM) [3]. Numerous studies that examined the tumor suppressive and/or proapoptotic effect 
of ATO have revealed the molecular mechanism by which ATO exerts an anticancer effect in both solid cancer and hematological malignancies (see below section). Thus, accumulating evidence implicates ATO and/or other arsenicals in clinical use as a promising drug to treat cancer patients. Besides ATO monotherapy, there is a growing body of evidence that ATO may be a favorable drug when combined with not only conventional anticancer therapeutics including radiation and chemotherapy but also recently developed molecular-targeted drugs. In one example, the combined treatment of all-trans-retinoic acid (ATRA) with ATO has been shown to synergistically induce apoptosis of APL cells and clinically shown to be better outcome and less toxicity than the combined treatment of ATRA with chemotherapy in the treatment of patients with APL $[4,5]$. This chapter summarizes the anticancer effect of ATO-based combination therapies in different types of solid cancer and hematological malignancies. Furthermore, the molecular mechanism by which ATO-based combination therapies exert a proapoptotic effect in cancer cells is discussed.

\section{Novel arsenic-based combinatorial anticancer therapy}

Based on the promising effect of arsenic on apoptosis in cancer cells, it has been further utilized as a combinatorial drug with other chemotherapeutic agents and/or molecular-targeted drugs to gain its anticancer effect in various types of cancer. The combination drugs, possible target molecules, molecular basis underlying combination treatment-induced apoptosis, and combination indices (CI) for each cancer are summarized in Figure 1 and Table 1.

\subsection{Solid cancer}

\subsubsection{Colon cancer}

Lee et al. reported that sulindac, a nonsteroidal anti-inflammatory drug (NSAID), enhances ATO-induced apoptosis by inhibiting NF- $\kappa$ B activation mediated through the blocking of phosphorylation and degradation of IкB-alpha in HCT-116 cells [6]. In addition, Cai et al. reported that combined ATO-PI3K inhibitor LY294002 treatment synergistically suppresses the proliferation of colon cancer cell lines, where ATO decreases Hh pathway transcription factor Gli1 and its downstream gene expression including BCL2 and CCND1 [7].

\subsubsection{Prostate cancer}

Therapeutics in prostate cancer is based on the progression stage of the cancer, and radiation therapy is widely utilized for treatment. ATO was reported to enhance the radiation sensitivity of androgen-dependent ( $\mathrm{LNCaP}$ ) and androgen-independent (PC-3) human prostate cancer cells by mediating inhibition of the Akt/mTOR signaling pathway both in vitro and in vivo [8]. As shown in colon cancer, it has been reported that ATO inhibits the proliferation of the prostate cancer cell line PC-3 by suppressing the Hh signaling pathway and the tumor suppression effect was further enhanced by a classic Hh pathway inhibitor cyclopamine in vivo [9]. Furthermore, 


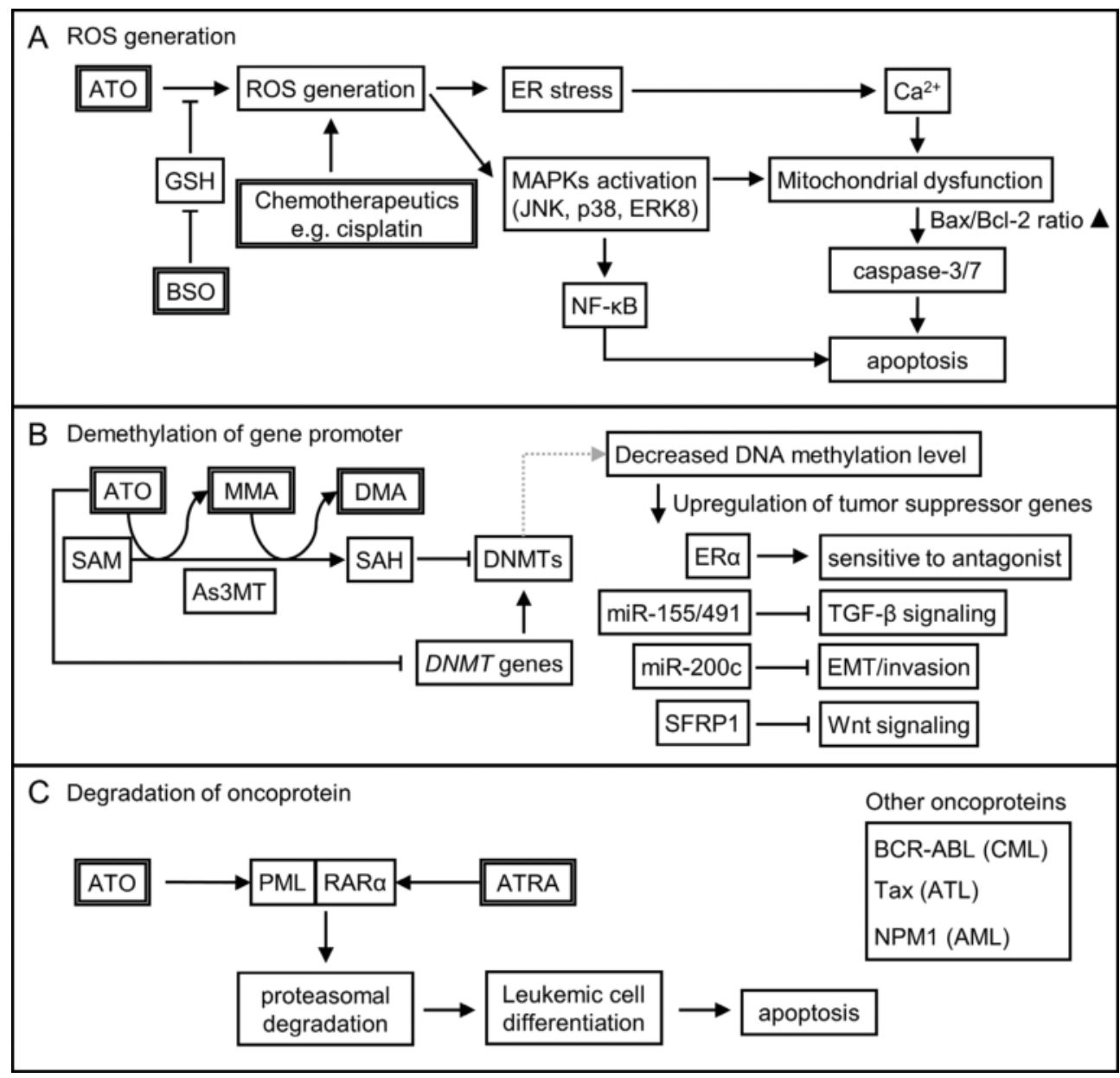

Figure 1. Molecular mechanism by which ATO exerts an anticancer effect synergistically with other therapeutics. (A) In most cancer cells, ATO generates intracellular ROS, which potentially triggers activation of the apoptotic signaling pathway. A glutathione synthesis inhibitor BSO enhances the effect of ATO-induced ROS generation by depleting GSH [43, 60], while a platinum drug CDDP cooperatively enhances ROS generation [12]. ROS-induced ER stress as well as MAPK phosphorylation can occur in mitochondrial dysfunction, which subsequently activates caspase-3/caspase-7 and induces apoptosis. (B) Arsenite methyltransferase (As3MT)-mediated metabolic methylation of ATO decreases methyl donors (S-adenosylmethionine (SAM)) and increases its metabolite S-adenosyl-L-homocysteine (SAH), which may inhibit DNA methyltransferase activity of DNMT. ATO itself downregulates gene expression of DNMTs [117]. Consequently, promoter demethylation of silenced genes, including miR-155, miR-200c, secreted frizzled-related protein-1 (SFRP1), and $E R \alpha$, upregulates their gene expression, which may exert anticancer activities [22, 118-120]. The demethylation effect of ATO and other anticancer therapeutics may cooperatively induce apoptosis in cancer cells. (C) In APL cells, ATO binds to PML, while ATRA binds to RAR $\alpha$. Thus, combined ATO-ATRA treatment synergistically induces proteasomal degradation of PML-RAR $\alpha$ oncoprotein, differentiation, and subsequent apoptosis [73]. ATO also can induce proteasomal degradation of oncoproteins including chimeric protein BCR-ABL (generated in CML cells), Tax (HTLV-I-encoded protein), and NPM1 (frequently mutated in AML cells). ATO and combination agents are indicated in the Double Square. MMA, monomethylarsonous acid; DMA, dimethylarsinous acid. 


\begin{tabular}{|c|c|c|c|c|}
\hline Combination regime & Cancer type & CI value & Mechanism of action & Ref. \\
\hline \multirow[t]{5}{*}{ ATO + radiotherapy } & Prostate cancer & - & $\begin{array}{l}\text { Inhibition of Akt/mTOR } \\
\text { signaling pathway }\end{array}$ & [8] \\
\hline & Oral cancer & - & $\begin{array}{l}\text { Inhibition of tumor growth, } \\
\text { angiogenesis, and metastasis }\end{array}$ & {$[11]$} \\
\hline & Cervical cancer & - & $\begin{array}{l}\text { Suppression of radiation- } \\
\text { induced MMP-9 expression, } \\
\text { ROS generation-induced } \\
\text { MAPKs activation, and Bax } \\
\text { translocation }\end{array}$ & {$[18,19]$} \\
\hline & Breast cancer & - & Bcl-2/Bax ratio & [23] \\
\hline & Glioma & - & $\begin{array}{l}\text { Increased mitotic arrest } \\
\text { and regulation of PI3K/Akt } \\
\text { and ERK1/ERK2 signaling } \\
\text { pathways }\end{array}$ & [53] \\
\hline \multirow[t]{3}{*}{ ATO + cisplatin (CDDP) } & Oral cancer & $0.34-0.92$ & $\begin{array}{l}\text { ROS generation, decrease } \\
\text { in Bcl-2 protein level, and } \\
\text { constitutive activation of } \\
\text { caspase-3 }\end{array}$ & {$[12]$} \\
\hline & Ovarian cancer & $0.63-0.93$ & $\begin{array}{l}\text { Upregulation of } B A X \text { and TP53 } \\
\text { and downregulation of } H I F 1 A \text {, } \\
I G F 1 R, M E T \text {, and } A R \text { (effects } \\
\text { by only ATO) }\end{array}$ & [15] \\
\hline & Lung cancer & $0.5-0.6$ & $\begin{array}{l}\text { Increases in Bax and decreases } \\
\text { in Bcl-2 and clusterin }\end{array}$ & {$[44]$} \\
\hline $\mathrm{TAO}\left(\mathrm{As}_{4} \mathrm{O}_{6}\right)+\mathrm{CDDP}$ & Cervical cancer & - & $\begin{array}{l}\text { Synergistic activation of } \\
\text { caspase-3 }\end{array}$ & [21] \\
\hline \multirow[t]{8}{*}{$\begin{array}{l}\text { ATO + all-trans-retinoic } \\
\text { acid (ATRA) }\end{array}$} & Glioma & - & $\begin{array}{l}\text { Suppression of cancer stem cell } \\
\text { (CSC) properties }\end{array}$ & {$[61]$} \\
\hline & Hepatoma & - & Reduced GSH level & [67] \\
\hline & Lung adenocarcinoma & - & & \\
\hline & Breast cancer & - & & \\
\hline & $\begin{array}{l}\text { Acute promyelocytic } \\
\text { leukemia (APL) }\end{array}$ & - & $\begin{array}{l}\text { ATO and APL differentially } \\
\text { induce proteasomal } \\
\text { degradation of PML-RAR } \alpha\end{array}$ & [73] \\
\hline & $\begin{array}{l}\text { Acute myeloid } \\
\text { leukemia (AML)/ } \\
\text { FLT3-ITD }\end{array}$ & - & $\begin{array}{l}\text { Co-inhibition of FLT3 signaling } \\
\text { pathways }\end{array}$ & [85] \\
\hline & AML/NPM1-mutated & - & $\begin{array}{l}\text { Degradation of nucleophosmin } \\
\text { (NPM1) }\end{array}$ & [86] \\
\hline & $\begin{array}{l}\text { Adult T-cell leukemia } \\
\text { (ATL)/RAR } \alpha \text {-positive }\end{array}$ & - & $\begin{array}{l}\text { Degradation of HTLV-I } \\
\text { transactivator protein (Tax) }\end{array}$ & [118] \\
\hline
\end{tabular}




\begin{tabular}{|c|c|c|c|c|}
\hline Combination regime & Cancer type & CI value & Mechanism of action & Ref. \\
\hline \multirow[t]{5}{*}{$\begin{array}{l}\text { ATO + buthionine } \\
\text { sulfoximine (BSO) }\end{array}$} & Ovarian cancer & - & $\begin{array}{l}\text { GSH depletion, increased } \\
\text { intracellular ROS generation, } \\
\text { and activation of oxidative } \\
\text { stress-related pathway }\end{array}$ & [17] \\
\hline & Lung cancer & - & GSH depletion & [43] \\
\hline & Glioma & - & GSH depletion & [60] \\
\hline & AML & - & $\begin{array}{l}\text { ROS-mediated } \\
\text { phosphorylation of JNK } \\
\text { and } \mathrm{BIM}_{\mathrm{EL}} \text { and induction of } \\
\text { intrinsic apoptosis }\end{array}$ & [87] \\
\hline & $\begin{array}{l}\text { Lymphoma and } \\
\text { leukemia }\end{array}$ & - & $\begin{array}{l}\text { ROS-mediated phosphorylation } \\
\text { of JNK and upregulation of } \\
\text { death receptor } 5\end{array}$ & [88] \\
\hline \multirow[t]{2}{*}{$\mathrm{ATO}+$ bortezomib (BOR) } & Multiple myeloma & $0.4-0.64$ & $\begin{array}{l}\text { Synergistic effect of ATO/BOR } \\
\text { with p38 inhibitor (SB203580) } \\
\text { on Bcl-2 downregulation and } \\
\text { apoptosis in MM cell lines }\end{array}$ & [97] \\
\hline & Mantle cell lymphoma & $<1.0$ & $\begin{array}{l}\text { Inhibition of NF- } \kappa \text { B activity, } \\
\text { decreases in cyclin D1 } \\
\text { and Bcl-2 expression, and } \\
\text { decreased interaction of Mcl-1 } \\
\text { with Bak }\end{array}$ & {$[114,115]$} \\
\hline \multirow[t]{3}{*}{$\begin{array}{l}\text { ATO + interferon- } \alpha \\
(\mathrm{IFN}-\alpha)\end{array}$} & $\begin{array}{l}\text { Chronic myelogenous } \\
\text { leukemia (CML) }\end{array}$ & - & $\begin{array}{l}\text { Suppressive activity of CML } \\
\text { leukemia-initiating cells }\end{array}$ & [108] \\
\hline & ATL & - & $\begin{array}{l}\text { Degradation of HTLV-I } \\
\text { transactivator protein (Tax) }\end{array}$ & {$[109,110]$} \\
\hline & $\begin{array}{l}\text { Primary effusion } \\
\text { lymphoma }\end{array}$ & - & Inhibition of NF- $\kappa$ B activity & {$[111]$} \\
\hline
\end{tabular}

Combination index value $(\mathrm{CI})$; synergism is indicated by $\mathrm{CI}<1$.

Table 1. Summary of representative ATO-based combination strategies to treat cancer.

Tai et al. reported that combined ATO-mTOR inhibitor RAD001 (everolimus) treatment synergistically induces both apoptosis and autophagy in prostate cancer cells, where enhanced autophagic cell death was accompanied by increased Beclin1 mRNA stability as well as upregulation of ATG5-ATG12 conjugate, Beclin1, and LC3-LC2 [10]. Importantly, the study showed that ATO-RAD001 combinatorial treatment more significantly suppresses LNCaP xenograft tumor proliferation than monotherapy without enhancing weight loss [10].

\subsubsection{Oral cancer (oral squamous cell carcinoma (OSCC))}

OSCC is the most common head and neck neoplasm and is highly associated with poor prognosis, despite advances that have been made in diagnostic and therapeutic strategies such as surgery, chemotherapy, and radiotherapy. ATO was reported as a combinatorial drug with radiotherapy [11] and a platinum-based antineoplastic drug cisplatin (CDDP) [12], both of which 
are the most standard therapies for OSCC. Since ATO/CDDP-induced apoptosis was almost completely abrogated by NAC, ROS generation may be closely associated with the tumor suppression effect (Figure 1A) [12]. Recent publications also implicated the therapeutic application of arsenic in the treatment for OSCC. Wang et al. reported that nicotinamide phosphoribosyltransferase (NAMPT) increases in patients with OSCC and a NAMPT inhibitor FK866 and ATO cooperatively induced apoptosis and depletes intracellular nicotinamide adenine dinucleotide levels in OSCC cell lines [13]. Tsai et al. showed that the combined ATO-dithiothreitol (DTT) treatment increases proapoptotic molecules Bax and Bak and decreases Bcl-2 and p53, which leads to a significant cell death of oral cancer cells but not the non-tumor cells [14].

\subsubsection{Ovarian cancer}

The rate of the mortality from ovarian cancer is highest among malignant tumors of the female genital organs. As indicated in other types of cancer, ATO was reported to exert synergistic cytotoxic effects against ovarian cancer cells when it was combined with CDDP, one of the standard chemotherapeutics for ovarian cancer, and/or mTOR inhibitor RAD001 [15, 16]. Ong et al. reported that both buthionine sulfoximine and ascorbic acid differentially enhance ATO-mediated cell killing by mediating GSH depletion and the oxidative stress-related pathway, respectively [17].

\subsubsection{Cervical cancer}

Radiotherapy has been generally used for the treatment of patients with cervical cancer, which is the most common cancer among females worldwide, as a monotherapy and combined therapy with chemotherapeutics, such as platinum-based drugs. The combined ATO-radiation treatment was expectably reported to exert a beneficial antitumoral effect on cervical cancer cells in vitro and/or in vivo $[18,19]$. Wei et al. reported that ATO decreases radiation-accelerated lung metastases probably via suppression of radiation-induced MMP-9 expression [18]. Kang et al. reported that ATO enhances the translocation of Bax protein to mitochondria and the phosphorylation level of Bcl-2, which were accompanied by activation of MAPKs including p38 and JNK [19]. Since NAC clearly inhibits the ATO-mediated cell killing as well as MAPK activation, ROS generation may play an important role in ATO-radiation-induced apoptosis. In addition to ATO, tetraarsenic oxide $\left(\mathrm{TAO}, \mathrm{As}_{4} \mathrm{O}_{6}\right)$ was shown to potentially exert an anticancer effect on cervical cancer cells. Kim et al. reported that the combined TAO and radachlorin/photodynamic therapy cooperatively suppress the proliferation of mouse TC- 1 cells both in vitro and in vivo, where tumor suppressor p53 and the inducible p21 protein increased especially in combined treated tumor cells [20]. TAO was also reported to synergistically suppress tumor growth of human cervical carcinoma cell line CaSki when it was combined with CDDP [21]. The combined TAO-CDDP therapy dramatically increased the number of apoptotic cells, as similarly observed in other types of cancer cells when ATO was combined with CDDP $[12,15]$.

\subsubsection{Breast cancer}

Breast cancer is one of the leading causes of cancer-related deaths among women worldwide. In breast cancer cells, ATO was reported to reduce the expression of DNA methyltransferase-1 (DNMT1) and to induce the expression of estrogen receptor $\alpha$ (ER $\alpha)$, whose expression has been epidemiologically recognized to increase disease-free survival and indicate an overall 
better prognosis (Figure 1B) [22]. Subsequently, combined ATO and antiestrogen tamoxifen (TAM) therapy coordinately suppressed tumor growth of a human breast cancer cell line MDA-MB-435S both in vitro and in vivo [22]. ATO was reported to enhance ${ }^{89} \mathrm{Sr}$ radiation treatment-induced apoptosis by partly modulating the Bcl-2/Bax ratio [23]. Guilbert et al. reported that ATO suppresses rapamycin (specific mTOR inhibitor)-induced phosphorylation of both ERK and Akt (Ser473), which leads to enhancement of the anticancer effect of rapamycin in vivo [24]. Cotylenin $\mathrm{A}(\mathrm{CN}-\mathrm{A})$, a plant growth regulator, was reported to exert a favorable antitumor effect on breast cancer cells when it was co-incubated with ATO in vitro [25]. The combined CN-A-ATO treatment decreased survivin expression and increased caspase-7 expression by partly mediating ROS generation [25]. It has been reported that melatonin, a known natural antioxidant, enhances ATO-induced apoptosis by mediating ROS generation-induced MAPK activation including p38 and JNK in human breast cancer cell lines MDA-MB-231 and SK-BR-3 [26]. They also showed that mTOR inhibitor rapamycin further enhances the ATO-melatonin-induced apoptosis [26]. In addition to inorganic arsenite ATO, its intermediate metabolites monomethylarsonous acid (MMA $\left.{ }^{\mathrm{II}}\right)$ and dimethylarsinous acid (DMA $\left.{ }^{\mathrm{II}}\right)$ exert more cytotoxicity toward breast cancer cells than ATO, implicating application of the arsenite-related intermediates in anticancer therapy for breast cancer [27]. The combined intermediates $\mathrm{MMA}^{\mathrm{III}}$ and $\mathrm{DMA}^{\mathrm{III}}$ cryptotanshinone (a natural quinoid diterpene isolated from Salvia miltiorrhiza roots) strongly induce apoptosis by mediating endoplasmic reticulum (ER) stress and/or ROS generation in MCF-7 cells [27].

\subsubsection{HCC and bile duct carcinoma (cholangiocarcinoma)}

Hepatocellular carcinoma (HCC) is the most common primary liver malignancy, which is the sixth most common type of cancer worldwide. Sorafenib, a known multikinase inhibitor, can extend the survival rate of patients with advanced HCC. ATO was reported to synergize with sorafenib to inhibit the proliferation and promote the apoptosis of HCC cells by diminishing the sorafenib-induced activation of Akt and/or its downstream factors, including glycogen synthase kinase- $3 \beta$, mTOR, ribosomal protein S6 kinase, and eukaryotic translation initiation factor $4 \mathrm{E}$-binding protein 1 [28]. ATO was also reported to potentiate the anticancer effect of genistein [29], 3'-azido-3'-deoxythymidine (AZT) [30], oridonin [31], MDM2 inhibitor nutlin-3 [32], metformin [33-34], survivin mutant (T34A) [35], shikonin [36], and andrographolide [37] in HCC cells.

\subsubsection{Lung cancer}

Lung cancer is the most common type of cancer worldwide. As indicated in colon cancer, there are several reports regarding the synergistic induction of apoptosis by an NSAID sulindac and ATO in human lung cancer cell lines [38, 39]. Combined ATO-sulindac treatment induced apoptosis of human non-small cell lung cancer (NSCLC) cell line A549 by mediating the mitochondrial pathway and the NF- $\kappa$ B pathway [38] and by mediating p53-induced downregulation of survivin [39]. It has also been reported that combined ATO-sulindac treatment induces synergistic augmentation of cytotoxicity in both human NSCLC cell lines NCI-H157 and NCI-H1299 by mediating ROS-induced MAPK phosphorylation and via c-Jun $\mathrm{NH}_{2}$-terminal kinase-dependent Bcl-xL phosphorylation, respectively [40,41]. Indomethacin, a nonselective cyclooxygenase inhibitor (a structural isoform of sulindac), was also shown to enhance the ATO-induced cytotoxic effect in A549 cells by mediating activation of ERK and/or p38 MAPKs [42]. Han et al. 
reported that buthionine sulfoximine (BSO), a glutathione synthesis inhibitor, enhances ATOinduced apoptosis in A549 cells, in which the apoptosis was related to the increased level of intracellular ROS (Figure 1A) [43]. In addition, combined ATO-CDDP treatment induced apoptosis and synergistically suppressed the proliferation of human NSCLC cell lines A549 and $\mathrm{H} 460$, with $\mathrm{CI}$ values 0.5 and 0.6 , respectively, where $\mathrm{CI}<1$ defines synergism [44]. Lam et al. indicated that combined treatment with ATO and a selective fibroblast growth factor receptor (FGFR) inhibitor PD173074 cooperatively suppresses tumor proliferation both in vitro and in vivo in the lung squamous cell carcinoma (SCC) cell line SK-MES-1, in which ATO-PD173074 decreased FGFR1, Akt, Src, c-Raf, and Erk, at least in part by mediating proteasomal degradation [45]. Gu et al. reported that ROS-mediated ER stress and mitochondrial dysfunction were involved in the apoptosis induced by resveratrol and ATO in A549 cells [46].

\subsubsection{Gastric cancer}

In gastric cancer, ATO and ABT-737, a small-molecule drug that inhibits Bcl-2/Bcl-xL antiapoptotic molecules, cooperatively suppressed the proliferation of human gastric cancer cell lines SGC7901 and MGC-803 [47]. Although ABT-737 has low solubility and oral bioavailability, the other Bcl-2 inhibitor ABT-199 has been developed for clinical use for the treatment of hematological malignancies including chronic lymphoid leukemia (CLL) [48].

\subsubsection{Urothelial carcinoma (UC)}

In urothelial carcinoma, Kuo et al. reported that 2-methoxyestradiol (2-ME), an endogenous derivative of $17 \beta$-estradiol, elicits synergistic cytotoxicity of human UC cell lines NTUB1 and T24 in combination with ATO, with a $\mathrm{CI}<1.0$ [49].

\subsubsection{Pancreatic cancer}

In pancreatic cancer, Wang et al. reported that parthenolide (PTL), a sesquiterpene lactone from the medical herb feverfew, enhances apoptosis of human pancreatic cancer cell lines PANC-1 and BxPC-3 by mediating ROS generation and subsequent caspase activation via the mitochondrial pathway [50]. The combined ATO-PTL treatment significantly reduced tumor growth rates of PANC-1 xenografts compared with those treated with either PTL or ATO alone [50]. Another report focused on the limited efficacy of ATO on cytotoxicity in pancreatic ductal adenocarcinoma probably because of the high-cellular ROS scavenging activity. Lang et al. reported that PX-478, a hypoxia-inducible factor-1 inhibitor, robustly strengthens the antigrowth and proapoptosis effect of ATO on Panc-1 and BxPC-3 pancreatic cancer cells in vitro by mediating ROS accumulation [51].

\subsubsection{Glioma and glioblastoma (GBM)}

In glioma, several reports indicated the effectiveness of arsenic for combination therapy. Kim et al. reported that ATO specifically increases expression of death receptor 5 (DR5), a death receptor of tumor necrosis factor-related apoptosis-inducing ligand (TRAIL) in a subset of human glioma cell lines but not in astrocytes [52]. They also showed that combined ATO and TRAIL treatment synergistically reduces the survival of glioma cells, with a CI $<1.0$ [52]. 
ATO-radiation combination treatment enhanced autophagic effects in U118-MG cells through increased mitotic arrest and regulation of PI3K/Akt and ERK1/2 signaling pathways [53]. Similar observations were reported in human fibrosarcoma and osteosarcoma, where the combined treatment arrested their cell cycle at the $\mathrm{G}_{2} / \mathrm{M}$ phase $[54,55]$. ATO is a ROS inducer, and heme oxygenase-1 (HO-1) is known to be increased in arsenic-treated cells [56]. Liu et al. reported that HO-1 inhibition or Nrf2 knockdown significantly potentiated ATO-induced cytotoxic effects on glioma cells [57]. This result suggests that ATO-induced gene expression including the Nrf2 signaling pathway may be partly involved in the resistance of cancer cells to ATO. Dizaji et al. reported that combined treatment with ATO and silibinin, a natural polyphenolic flavonoid, synergistically induces apoptosis and inhibits invasiveness in the human GBM cell line U87MG, in which the expression of cathepsin B, uPA, MMP-2, MMP-9, membrane type 1-MMP, survivin, Bcl-2, and CA9 decreased after treatment [58]. Gülden et al. reported that combined treatment with ATO and silibinin reduces the viability of A-172 by mediating intracellular arsenic accumulation [59]. As described in lung cancer, BSO depleted cellular glutathione and acted synergistically with ATO in rat C6 astroglioma cells [60]. Karsy et al. investigated the effect of ATO and ATRA on neurosphere formation of U87MG possessing wild-type (wt) p53 and/ or codon-specific p53 mutant (R273H) [61]. They found that ATO and ATRA treatment could induce apoptosis of both U87-p53 (wt) and U87-p53 (R273H) and could potently suppress CSC properties in vitro [61]. It is well known that c-Myc is also required for the maintenance of CSCs of various cancers including GBM [62]. Yoshimura et al. showed that ATO and c-Myc inhibitor 10058-F4 coordinately enhanced differentiation of GBM CSCs and regressed GBM CSC tumor growth in vivo [63]. Primon et al. reported the involvement of cathepsin L (CatL) in the ATOinduced apoptotic effect $[64,65]$. They found that knockdown of CatL enhances ATO-mediated in vitro cytotoxicity and apoptosis in both the GBM cell line U87MG [58] and pilocytic astrocytoma cell line MPA58 [65].

\subsubsection{Other combinations}

Baumgartner et al. reported that ATO-mediated apoptosis is markedly enhanced by using the polyunsaturated fatty acid docosahexaenoic acid (DHA) in 12 different ATO-resistant solid tumor cell lines including breast, ovarian, colon, prostate, cervical, and pancreatic cancer, while there was no cytotoxicity in normal skin fibroblasts, human microvascular endothelial cells, and peripheral blood mononuclear cells derived from healthy donors [66]. Lin et al. reported that combined ATRA and ATO treatment synergistically inhibits the proliferation and induces apoptosis in human hepatoma, breast cancer, and lung cancer cells in vitro [67]. Kryeziu et al. found that combined treatment with ATO and erlotinib, a selective EGFR inhibitor, acts synergistically through accumulation of DNA damage by inhibiting EGFR-mediated DNA double-strand break repair in mesothelioma, HCC, colorectal carcinoma, osteosarcoma, thyroid carcinoma, and cervix carcinoma in vitro [68].

\subsection{Hematological malignancies}

\subsubsection{Acute promyelocytic leukemia (APL)}

Patients with newly diagnosed APL, also known as a AML M3 subtype with APL-specific chromosomal translocation $\mathrm{t}(15 ; 17)(\mathrm{q} 22 ; \mathrm{q} 21)$ and PML/RAR $\alpha$ chimeric fusion protein, are mostly 
cured after standard ATRA with chemotherapy, while toxicity and refractoriness to the treatment are observed in some patients. Accumulating evidence shows the superiority of novel combined ATRA and ATO therapy for the treatment of patients with APL in terms of event-free survival, relapse-free survival, and less hematologic toxicity, compared to ATRA with chemotherapy $[4,5$, 69-72]. The molecular basis underlying synergistic effects between ATRA and ATO has been biologically demonstrated. ATRA and ATO differentially bind PML/RAR $\alpha$ protein, the proteasomal degradation of which readily induces terminal differentiation, and subsequent apoptosis in APL cells (Figure 1C) [73]. In addition to the effect of ATO on the PML moiety, ATO-induced anticancer activities including inhibition of leukemic progenitor self-replication and antiangiogenic effects might be involved in the antileukemic activity. The combined ATRA with intravenous administration of ATO has been developed to combine ATRA with oral As4S4 administration as a routine treatment option for appropriate patients [74]. Moreover, Wang et al. showed that the combination of low concentrations of As4S4 and $\mathrm{As}^{3+}$ enhanced degradation of the PML/RAR $\alpha$ oncoprotein and subsequent apoptosis [75]. Other modified combination regimes have been demonstrated using in vitro experimental models [76-82]. Jung et al. reported that the Src family kinase inhibitor PP2 enhances differentiation of APL cells induced by ATRA-ATO treatment [76]. Rogers et al. reported that vitamin D3 potentiates the antitumorigenic effects of ATO in HL-60 cells (PML/RAR $\alpha$-negative APL cell line) by enhancing nuclear DNA fragmentation [77]. The antileukemic activity of ATO was also enhanced by the combination strategies with granulocytemonocyte colony stimulation factor [78], a noncalcemic vitamin D analog 19-Nor-1,25(OH)2D2 [79], N-(beta-Elemene-13-yl) tryptophan methyl [80], a selective inhibitor of epidermal growth factor receptor (EGFR) gefitinib [81], and high-dose vitamin C (ascorbic acid) [82], all of which enhance ATO-induced differentiation and apoptosis of APL cells.

\subsubsection{Acute myeloid leukemia (AML)}

AML is a malignant disease of the bone marrow, where juvenile leukocytes are arrested in an early stage of differentiation. It has been reported that AML patients with FLT mutations including FLT3-internal tandem duplication (FLT3-ITD) had significantly shorter overall and disease-free survival [83]. Takahashi et al. reported that combined treatment with ATO and FLT3-specific inhibitor AG1296 synergistically induces apoptosis in FLT3-ITD-positive cells, but not in Flt3 wild-type cells [84]. The combined ATO with ATRA, a novel standard treatment for patients with APL, was shown to exert synergistic cytotoxicity against FLT3-ITD AML cells via co-inhibition of FLT3 signaling pathways [85]. In addition, ATO-ATRA was shown to induce apoptosis of NPM1-mutated AML cells by targeting nucleophosmin (NPM1) oncoprotein, whose mutation possibly represents a therapeutic target because of high frequency in $>30 \%$ AML [86]. As indicated in lung cancer and glioma, BSO was shown to enhance the ATOinduced anticancer effect by mediating ROS generation in AML cells [87] and other leukemic/lymphoma cells [88], suggesting that combined ATO-BSO treatment would be one of the attractive alternative therapies for cancer treatment. It has also been reported that combined treatment with ATO and dichloroacetate [89], azacytidine [90], rapamycin [91], and aclacinomycin A [92] enhances apoptosis in AML cells. Wang et al. reported that ethacrynic acid and a derivative enhance apoptosis in ATO-treated myeloid leukemia and lymphoma cell lines; this combination treatment generates high levels of ROS, activates JNK, and subsequently decreases the protein level of antiapoptotic molecule Mcl-1 [93]. 


\subsubsection{Multiple myeloma (MM)}

ATO, melphalan, and ascorbic acid (AA) combination therapy (MAC) is a therapeutic option for patients with relapsed or refractory MM [94]. Grad et al. initially showed that clinically relevant doses of AA decrease GSH levels and potentiate ATO-mediated cell death of MM cell lines [95]. Current therapeutics for MM, such as a proteasome inhibitor, namely, bortezomib (BOR) and carfilzomib, and immunomodulatory drugs, namely, thalidomide, lenalidomide (LEN), and pomalidomide, have successfully improved the patient survival, though MM remains an incurable disease [96]. In view of the current MM therapeutics, ATO was reported to enhance the anti-myeloma cytotoxicity of BOR [97] and sensitivity of MM cells to lenalidomide (LEN) [98]. Wen et al. showed that the enhanced cytotoxicity of ATO-BOR is associated with augmented STAT3 inhibition, JNK activation, and upregulation of Bim, p21, p27, and p53 as well as downregulation of Bcl-2 [97]. Jian et al. showed that ATO upregulates cereblon, the antimyeloma target of LEN, thus potentiating the sensitivity of MM cells [98]. The anti-myeloma activity of ATO was also enhanced by the combination strategies with a vitamin E analog Trolox [99], a specific MEK inhibitor PD325901 [100], a natural quinoid diterpene cryptotanshinone (also known as STAT3 inhibitor) [101, 102], and a phytochemical sulforaphane [103].

\subsubsection{Chronic myelogenous leukemia (CML)}

Recent therapeutics for CML were developed by targeting the Bcr-Abl fusion protein generated from a Philadelphia $(\mathrm{Ph})$ chromosome with reciprocal translocation of chromosomes 9 and 22. Despite the advances in CML therapeutics including Bcr-Abl tyrosine kinase inhibitors (TKIs), TKI therapy can produce a subpopulation of CML cells with a Bcr-Abl gene mutation that leads to resistance to TKI therapy, which results in a poorer prognosis in $10-15 \%$ of patients with CML. Several reports indicated the efficacy of ATO-based combined therapy for CML cells [104-108]. Du et al. reported that combined treatment of ATO with imatinib, which is the first approved TKI, coordinately enhances apoptosis of CML cells by mediating intrinsic (upregulation of BAX), extrinsic (upregulation of TNFR1, CASP8, and CASP10), and ER stressrelated pathways (HSPA5 and DDIT3) [104]. Wang et al. also showed the additive effect of ATOnilotinib, a second-line TKI agent, on the proliferation and differentiation of primary leukemic cells from patients with CML in blast crisis [105]. In addition, combined nilotinib-ATO treatment induces ER stress-mediated apoptosis in imatinib-resistant K562 cells by mediating JNK activation [106]. Li et al. reported that anti-miR-21 oligonucleotide sensitizes K562 cells to ATO and enhances ATO-induced apoptosis probably by mediating upregulation of programmed cell death 4 (PDCD4) [107]. In a CML mice model, combined treatment with ATO and interferon- $\alpha$ (IFN- $\alpha$ ) was reported to be superior to imatinib [108] in terms of overall survival of secondary recipients, indicating that ATO-IFN- $\alpha$ may exhaust the activity of CML leukemia-initiating cells.

\subsubsection{Other leukemia and lymphoma}

As the efficacy was shown in a CML mice model [108], ATO and IFN- $\alpha$ synergized to induce cell cycle arrest and apoptosis in adult T-cell leukemia/lymphoma (ATL)-derived human T-cell lymphotropic virus type I (HTLV-I)-transformed cells [109, 110]. El-Sabban et al. reported that combined ATO-IFN- $\alpha$ treatment induces the degradation of Tax, which is the 
viral transactivator protein that plays a critical role in HTLV-I-induced transformation and apoptosis resistance [110]. Similarly, the enhanced ATO-IFN- $\alpha$-induced apoptosis was shown in primary effusion lymphoma [111]. Darwiche et al. showed that synergism of ATO-ATRA is especially observed in the HTLV-I-transformed cells expressing RAR $\alpha$ protein [112]. In acute lymphoblastic leukemia (ALL), low-dose ATO sensitized glucocorticoid-resistant ALL cells to dexamethasone via an Akt-dependent pathway [113]. Jung et al. and Zhao et al. independently showed the synergistic anticancer effects of ATO with BOR in mantle cell lymphoma, which is an aggressive and highly incurable B-cell non-Hodgkin lymphoma [114, 115]. Ding et al. recently reported that combined treatment of ATO with cucurbitacin B, an effective component of the dichloromethane extraction from Trichosanthes kirilowii maxim, synergistically enhances apoptosis by inhibiting STAT3 phosphorylation in Burkitt's lymphoma cell lines both in vitro and in vivo [116].

\section{Summary}

In this chapter, we show that arsenical compounds enhance cancer cell apoptosis when combined with other anticancer therapeutics including radiation, chemotherapies, and moleculartargeted drugs. Although a number of reports have shown the anticancer effects of arsenic and have discussed the possible molecular targets of ATO in malignant cells, molecular mechanisms underlying ATO-based synergistic anticancer effects with other anticancer therapeutics remain obscure. In the past decade, next-generation sequencing (NGS) technologies have tremendously improved and have clarified the whole context of genomic alterations in cancer cells, among which phenotypic and functional heterogeneity arises within the same tumor as a consequence of genetic changes, environmental differences, and anticancer therapy [121-123]. This indicates that the possibility of targeting single molecules and/or signaling pathways as well as single cellular biological processes may generate a different malignant population of cancer cells, some of which may acquire a certain drug resistance. Therefore, novel therapeutic agents and/or strategies are required to overcome drug resistance and improve both the disease outcome and the quality of life for patients with cancer. Further understanding of the relationship between induction of apoptosis and genetic/epigenetic changes in cancer cells may contribute to improvement in selectivity for cancer treatment. Additional studies are required to understand the synergistic anticancer action regarding ATO-based combination therapeutics to develop a novel combined therapy for cancer.

\section{Author details}

Akinobu Ota*, Md Wahiduzzaman and Yoshitaka Hosokawa

*Address all correspondence to: aota@aichi-med-u.ac.jp

Department of Biochemistry, Aichi Medical University School of Medicine, Nagakute, Aichi, Japan 


\section{References}

[1] Apperley JF. Chronic myeloid leukaemia. Lancet. 2015;385:1447-1459

[2] Zhu J, Chen Z, Lallemand-Breitenbach V, de The H. How acute promyelocytic leukaemia revived arsenic. Nature Reviews. Cancer. 2002;2:705-713

[3] Munshi NC, Tricot G, Desikan R, Badros A, Zangari M, Toor A, et al. Clinical activity of arsenic trioxide for the treatment of multiple myeloma. Leukemia. 2002;16:1835-1837

[4] Ravandi F, Estey E, Jones D, Faderl S, O'Brien S, Fiorentino J, et al. Effective treatment of acute promyelocytic leukemia with all-trans-retinoic acid, arsenic trioxide, and gemtuzumab ozogamicin. Journal of Clinical Oncology. 2009;27:504-510

[5] Abaza Y, Kantarjian H, Garcia-Manero G, Estey E, Borthakur G, Jabbour E, et al. Longterm outcome of acute promyelocytic leukemia treated with all-trans-retinoic acid, arsenic trioxide, and gemtuzumab. Blood. 2017;129:1275-1283

[6] Lee HR, Cheong HJ, Kim SJ, Lee NS, Park HS, Won JH. Sulindac enhances arsenic trioxide-mediated apoptosis by inhibition of NF-kappaB in HCT116 colon cancer cells. Oncology Reports. 2008;20:41-47

[7] Cai X, Yu K, Zhang L, Li Y, Li Q, Yang Z, et al. Synergistic inhibition of colon carcinoma cell growth by Hedgehog-Gli1 inhibitor arsenic trioxide and phosphoinositide 3-kinase inhibitor LY294002. OncoTargets and Therapy. 2015;8:877-883

[8] Chiu HW, Chen YA, Ho SY, Wang YJ. Arsenic trioxide enhances the radiation sensitivity of androgen-dependent and -independent human prostate cancer cells. PLoS One. 2012;7:e31579

[9] Xiong YJ, Guo YJ, Gao YR, Li S, Dai ZH, Dong XQ, et al. Synergism between arsenic trioxide and cyclopamine in the inhibition of PC3 cell survival via the Hedgehog signaling pathway. Neoplasma. 2015;62:894-904

[10] Tai S, Xu L, Xu M, Zhang L, Zhang Y, Zhang K, et al. Combination of arsenic trioxide and Everolimus (Rad001) synergistically induces both autophagy and apoptosis in prostate cancer cells. Oncotarget. 2017;8:11206-11218

[11] Kumar P, Gao Q, Ning Y, Wang Z, Krebsbach PH, Polverini PJ. Arsenic trioxide enhances the therapeutic efficacy of radiation treatment of oral squamous carcinoma while protecting bone. Molecular Cancer Therapeutics. 2008;7:2060-2069

[12] Nakaoka T, Ota A, Ono T, Karnan S, Konishi H, Furuhashi A, et al. Combined arsenic trioxide-cisplatin treatment enhances apoptosis in oral squamous cell carcinoma cells. Cellular Oncology (Dordrecht). 2014;37:119-129

[13] Wang XY, Wang JZ, Gao L, Zhang FY, Wang Q, Liu KJ, et al. Inhibition of nicotinamide phosphoribosyltransferase and depletion of nicotinamide adenine dinucleotide contribute to arsenic trioxide suppression of oral squamous cell carcinoma. Toxicology and Applied Pharmacology. 2017;331:54-61 
[14] Tsai CW, Yang MD, Hsia TC, Chang WS, Hsu CM, Hsieh YH, et al. Dithiothreitol enhanced arsenic-trioxide-induced cell apoptosis in cultured oral cancer cells via mitochondrial dysfunction and endoplasmic reticulum stress. Environmental Toxicology. 2017;32:17-27

[15] Zhang N, Wu ZM, McGowan E, Shi J, Hong ZB, Ding CW, et al. Arsenic trioxide and cisplatin synergism increase cytotoxicity in human ovarian cancer cells: Therapeutic potential for ovarian cancer. Cancer Science. 2009;100:2459-2464

[16] Liu N, Tai S, Ding B, Thor RK, Bhuta S, Sun Y, et al. Arsenic trioxide synergizes with everolimus (Rad001) to induce cytotoxicity of ovarian cancer cells through increased autophagy and apoptosis. Endocrine-Related Cancer. 2012;19:711-723

[17] Ong PS, Chan SY, Ho PC. Differential augmentative effects of buthionine sulfoximine and ascorbic acid in $\mathrm{As}_{2} \mathrm{O}_{3}$-induced ovarian cancer cell death: Oxidative stress-independent and -dependent cytotoxic potentiation. International Journal of Oncology. 2011;38: 1731-1739

[18] Wei LH, Lai KP, Chen CA, Cheng CH, Huang YJ, Chou CH, et al. Arsenic trioxide prevents radiation-enhanced tumor invasiveness and inhibits matrix metalloproteinase- 9 through downregulation of nuclear factor kappaB. Oncogene. 2005;24:390-398

[19] Kang YH, Lee SJ. Role of p38 MAPK and JNK in enhanced cervical cancer cell killing by the combination of arsenic trioxide and ionizing radiation. Oncology Reports. 2008;20:637-643

[20] Kim YW, Bae SM, Battogtokh G, Bang HJ, Ahn WS. Synergistic anti-tumor effects of combination of photodynamic therapy and arsenic compound in cervical cancer cells: In vivo and in vitro studies. PLoS One. 2012;7:e38583

[21] Byun JM, Jeong DH, Lee DS, Kim JR, Park SG, Kang MS, et al. Tetraarsenic oxide and cisplatin induce apoptotic synergism in cervical cancer. Oncology Reports. 2013;29:1540-1546

[22] Zhang W, Wang L, Fan Q, Wu X, Wang F, Wang R, et al. Arsenic trioxide re-sensitizes ER $\alpha$-negative breast cancer cells to endocrine therapy by restoring ER $\alpha$ expression in vitro and in vivo. Oncology Reports. 2011;26:621-628

[23] Liu H, Tao X, Ma F, Qiu J, Wu C, Wang M. Radiosensitizing effects of arsenic trioxide on MCF-7 human breast cancer cells exposed to 89 strontium chloride. Oncology Reports. 2012;28:1894-1902

[24] Guilbert C, Annis MG, Dong Z, Siegel PM, Miller WH Jr, Mann KK. Arsenic trioxide overcomes rapamycin-induced feedback activation of AKT and ERK signaling to enhance the anti-tumor effects in breast cancer. PLoS One. 2013;8:e85995

[25] Kasukabe T, Okabe-Kado J, Kato N, Honma Y, Kumakura S. Cotylenin A and arsenic trioxide cooperatively suppress cell proliferation and cell invasion activity in human breast cancer cells. International Journal of Oncology. 2015;46:841-848

[26] Yun SM, Woo SH, Oh ST, Hong SE, Choe TB, Ye SK, et al. Melatonin enhances arsenic trioxide-induced cell death via sustained upregulation of Redd1 expression in breast cancer cells. Molecular and Cellular Endocrinology. 2016;422:64-73 
[27] Zhang YF, Zhang M, Huang XL, Fu YJ, Jiang YH, Bao LL, et al. The combination of arsenic and cryptotanshinone induces apoptosis through induction of endoplasmic reticulum stress-reactive oxygen species in breast cancer cells. Metallomics. 2015;7:165-173

[28] Zhai B, Jiang X, He C, Zhao D, Ma L, Xu L, et al. Arsenic trioxide potentiates the anticancer activities of sorafenib against hepatocellular carcinoma by inhibiting Akt activation. Tumour Biology. 2015;36:2323-2334

[29] Chen C, Zhang Y, Wang Y, Huang D, Xi Y, Qi Y. Genistein potentiates the effect of arsenic trioxide against human hepatocellular carcinoma: Role of Akt and nuclear factor- $\kappa \mathrm{B}$. Cancer Letters. 2011;301:75-84

[30] Chen C, Zhang Y, Wang Y, Huang D, Xi Y, Qi Y. Synergic effect of 3'-azido-3'-deoxythymidine and arsenic trioxide in suppressing hepatoma cells. Anti-Cancer Drugs. 2011;22:435-443

[31] Chen G, Wang K, Yang BY, Tang B, Chen JX, Hua ZC. Synergistic antitumor activity of oridonin and arsenic trioxide on hepatocellular carcinoma cells. International Journal of Oncology. 2012;40:139-147

[32] Zheng T, Yin D, Lu Z, Wang J, Li Y, Chen X, et al. Nutlin-3 overcomes arsenic trioxide resistance and tumor metastasis mediated by mutant p53 in hepatocellular carcinoma. Molecular Cancer. 2014;13:133

[33] Yang X, Sun D, Tian Y, Ling S, Wang L. Metformin sensitizes hepatocellular carcinoma to arsenic trioxide-induced apoptosis by downregulating Bcl2 expression. Tumour Biology. 2015;36:2957-2964

[34] Ling S, Xie H, Yang F, Shan Q, Dai H, Zhuo J, et al. Metformin potentiates the effect of arsenic trioxide suppressing intrahepatic cholangiocarcinoma: Roles of p38 MAPK, ERK3, and mTORC1. Journal of Hematology \& Oncology. 2017;10:59

[35] Huang A, Yue D, Liao D, Cheng L, Ma J, Wei Y, et al. SurvivinT34A increases the therapeutic efficacy of arsenic trioxide in mouse hepatocellular carcinoma models. Oncology Reports. 2016;36:3283-3290

[36] Song J, Zhao Z, Fan X, Chen M, Cheng X, Zhang D, et al. Shikonin potentiates the effect of arsenic trioxide against human hepatocellular carcinoma in vitro and in vivo. Oncotarget. 2016;7:70504-70515

[37] Duan X, Li T, Han X, Ren J, Chen P, Li H, Gong S. The antitumor effect of arsenic trioxide on hepatocellular carcinoma is enhanced by andrographolide. Oncotarget. 2017;8: 90905-90915

[38] Jiang TT, Brown SL, Kim JH. Combined effect of arsenic trioxide and sulindac sulfide in A549 human lung cancer cells in vitro. Journal of Experimental \& Clinical Cancer Research. 2004;23:259-262

[39] Jin HO, Yoon SI, Seo SK, Lee HC, Woo SH, Yoo DH, et al. Synergistic induction of apoptosis by sulindac and arsenic trioxide in human lung cancer A549 cells via reactive oxygen species-dependent down-regulation of survivin. Biochemical Pharmacology. 2006;72:1228-1236 
[40] Park JH, Kim EJ, Jang HY, Shim H, Lee KK, Jo HJ, et al. Combination treatment with arsenic trioxide and sulindac enhances apoptotic cell death in lung cancer cells via activation of oxidative stress and mitogen-activated protein kinases. Oncology Reports. 2008;20:379-384

[41] Jin HO, Seo SK, WooSH, Lee HC, Kim ES, Yoo DH, et al. A combination of sulindac and arsenic trioxide synergistically induces apoptosis in human lung cancer H1299 cells via c-Jun NH2-terminal kinase-dependent Bcl-xL phosphorylation. Lung Cancer. 2008;61:317-327

[42] Mandegary A, Torshabi M, Seyedabadi M, Amirheidari B, Sharif E, Ghahremani MH. Indomethacin-enhanced anticancer effect of arsenic trioxide in A549 cell line: Involvement of apoptosis and phospho-ERK and p38 MAPK pathways. BioMed Research International. 2013;2013:237543

[43] Han YH, Kim SZ, Kim SH, Park WH. Induction of apoptosis in arsenic trioxide-treated lung cancer A549 cells by buthionine sulfoximine. Molecules and Cells. 2008;26:158-164

[44] Li H, Zhu X, Zhang Y, Xiang J, Chen H. Arsenic trioxide exerts synergistic effects with cisplatin on non-small cell lung cancer cells via apoptosis induction. Journal of Experimental \& Clinical Cancer Research. 2009;28:110

[45] Lam SK, Leung LL, Li YY, Zheng CY, Ho JC. Combination effects of arsenic trioxide and fibroblast growth factor receptor inhibitor in squamous cell lung carcinoma. Lung Cancer. 2016;101:111-119

[46] Gu S, Chen C, Jiang X, Zhang Z. ROS-mediated endoplasmic reticulum stress and mitochondrial dysfunction underlie apoptosis induced by resveratrol and arsenic trioxide in A549 cells. Chemico-Biological Interactions. 2016;245:100-109

[47] Sun XP, Zhang X, He C, Qiao H, Jiang X, Jiang H, et al. ABT-737 synergizes with arsenic trioxide to induce apoptosis of gastric carcinoma cells in vitro and in vivo. The Journal of International Medical Research. 2012;40:1251-1264

[48] Cang S, Iragavarapu C, Savooji J, Song Y, Liu D. ABT-199 (venetoclax) and BCL-2 inhibitors in clinical development. Journal of Hematology \& Oncology. 2015;8:129

[49] Kuo KL, Lin WC, Ho IL, Chang HC, Lee PY, Chung YT. 2-methoxyestradiol induces mitotic arrest, apoptosis, and synergistic cytotoxicity with arsenic trioxide in human urothelial carcinoma cells. PLoS One. 2013;8:e68703

[50] Wang W, Adachi M, Zhang R, Zhou J, Zhu D. A novel combination therapy with arsenic trioxide and parthenolide against pancreatic cancer cells. Pancreas. 2009;38:e114-e123

[51] Lang M, Wang X, Wang H, Dong J, Lan C, Hao J, et al. Arsenic trioxide plus PX-478 achieves effective treatment in pancreatic ductal adenocarcinoma. Cancer Letters. 2016; 378:87-96

[52] Kim EH, Yoon MJ, Kim SU, Kwon TK, Sohn S, Choi KS. Arsenic trioxide sensitizes human glioma cells, but not normal astrocytes, to TRAIL-induced apoptosis via CCAAT/ enhancer-binding protein homologous protein-dependent DR5 up-regulation. Cancer Research. 2008;68:266-275 
[53] Chiu HW, Ho SY, Guo HR, Wang YJ. Combination treatment with arsenic trioxide and irradiation enhances autophagic effects in U118-MG cells through increased mitotic arrest and regulation of PI3K/Akt and ERK1/2 signaling pathways. Autophagy. 2009;5:472-483

[54] Chiu HW, Lin JH, Chen YA, Ho SY, Wang YJ. Combination treatment with arsenic trioxide and irradiation enhances cell-killing effects in human fibrosarcoma cells in vitro and in vivo through induction of both autophagy and apoptosis. Autophagy. 2010;6:353-365

[55] Chiu HW, Lin W, Ho SY, Wang YJ. Synergistic effects of arsenic trioxide and radiation in osteosarcoma cells through the induction of both autophagy and apoptosis. Radiation Research. 2011;175:547-560

[56] Lee PC, Ho IC, Lee TC. Oxidative stress mediates sodium arsenite-induced expression of heme oxygenase-1, monocyte chemoattractant protein-1, and interleukin-6 in vascular smooth muscle cells. Toxicological Sciences. 2005;85:541-550

[57] Liu Y, Liang Y, Zheng T, Yang G, Zhang X, Sun Z, et al. Inhibition of heme oxygenase-1 enhances anti-cancer effects of arsenic trioxide on glioma cells. Journal of NeuroOncology. 2011;104:449-458

[58] Dizaji MZ, Malehmir M, Ghavamzadeh A, Alimoghaddam K, Ghaffari SH. Synergistic effects of arsenic trioxide and silibinin on apoptosis and invasion in human glioblastoma U87MG cell line. Neurochemical Research. 2012;37:370-380

[59] Gülden M, Appel D, Syska M, Uecker S, Wages F, Seibert H. Chrysin and silibinin sensitize human glioblastoma cells for arsenic trioxide. Food and Chemical Toxicology. 2017;105:486-497

[60] Klauser E, Gülden M, Maser E, Seibert S, Seibert H. Additivity, antagonism, and synergy in arsenic trioxide-induced growth inhibition of C6 glioma cells: Effects of genistein, quercetin and buthionine-sulfoximine. Food and Chemical Toxicology. 2014;67:212-221

[61] Karsy M, Albert L, Murali R, Jhanwar-Uniyal M. The impact of arsenic trioxide and alltrans retinoic acid on p53 R273H-codon mutant glioblastoma. Tumour Biology. 2014; $35: 4567-4580$

[62] Wang J, Wang H, Li Z, Wu Q, Lathia JD, McLendon RE. C-Myc is required for maintenance of glioma cancer stem cells. PLoS One. 2008;3:e3769

[63] Yoshimura Y, Shiino A, Muraki K, Fukami T, Yamada S, Satow T, et al. Arsenic trioxide sensitizes glioblastoma to a myc inhibitor. PLoS One. 2015;10:e0128288

[64] Primon M, Huszthy PC, Motaln H, Talasila KM, Torkar A, Bjerkvig R, et al. Cathepsin L silencing enhances arsenic trioxide mediated in vitro cytotoxicity and apoptosis in glioblastoma U87MG spheroids. Experimental Cell Research. 2013;319:2637-2648

[65] Primon M, Huszthy PC, Motaln H, Talasila KM, Miletic H, Atai NA, et al. Cathepsin L silencing increases $\mathrm{As}(2) \mathrm{O}(3)$ toxicity in malignantly transformed pilocytic astrocytoma MPA58 cells by activating caspases 3/7. Experimental Cell Research. 2017;356:64-73 
[66] Baumgartner M, Sturlan S, Roth E, Wessner B, Bachleitner-Hofmann T. Enhancement of arsenic trioxide-mediated apoptosis using docosahexaenoic acid in arsenic trioxideresistant solid tumor cells. International Journal of Cancer. 2004;112:707-712

[67] Lin LM, Li BX, Xiao JB, Lin DH, Yang BF. Synergistic effect of all-trans-retinoic acid and arsenic trioxide on growth inhibition and apoptosis in human hepatoma, breast cancer, and lung cancer cells in vitro. World Journal of Gastroenterology. 2005;11:5633-5637

[68] Kryeziu K, Jungwirth U, Hoda MA, Ferk F, Knasmüller S, Karnthaler-Benbakka C, et al. Synergistic anticancer activity of arsenic trioxide with erlotinib is based on inhibition of EGFR-mediated DNA double-strand break repair. Molecular Cancer Therapeutics. 2013;12:1073-1084

[69] Lo-Coco F, Avvisati G, Vignetti M, Thiede C, Orlando SM, Iacobelli S, et al. Retinoic acid and arsenic trioxide for acute promyelocytic leukemia. The New England Journal of Medicine. 2013;369:111-121

[70] Liang B, Zheng Z, Shi Y, Chen J, Hu X, Qian H, et al. Maintenance therapy with all-trans retinoic acid and arsenic trioxide improves relapse-free survival in adults with low- to intermediate-risk acute promyelocytic leukemia who have achieved complete remission after consolidation therapy. OncoTargets and Therapy. 2017;10:2305-2313

[71] Nasr R, Guillemin MC, Ferhi O, Soilihi H, Peres L, Berthier C, et al. Eradication of acute promyelocytic leukemia-initiating cells through PML-RARA degradation. Nature Medicine. 2008;14:1333-1342

[72] Tarkanyi I, Dudognon C, Hillion J, Pendino F, Lanotte M, Aradi J, et al. Retinoid/arsenic combination therapy of promyelocytic leukemia: Induction of telomerase-dependent cell death. Leukemia. 2005;19:1806-1811

[73] de Thé H, Chen Z. Acute promyelocytic leukaemia: Novel insights into the mechanisms of cure. Nature Reviews. Cancer. 2010;10:775-783

[74] Zhu HH, Wu DP, Jin J, Li JY, Ma J, Wang JX, et al. Oral tetra-arsenic tetra-sulfide formula versus intravenous arsenic trioxide as first-line treatment of acute promyelocytic leukemia: A multicenter randomized controlled trial. Journal of Clinical Oncology. 2013;3: $4215-4221$

[75] Wang S, Zhou M, Ouyang J, Geng Z, Wang Z. Tetraarsenictetrasulfide and arsenic trioxide exert synergistic effects on induction of apoptosis and differentiation in acute promyelocytic leukemia cells. PLoS One. 2015;10:e0130343

[76] Jung YS, Cheong HJ, Kim SJ, Kim KH, Lee N, Park HS, et al. Src family kinase inhibitor PP2 enhances differentiation of acute promyelocytic leukemia cell line induced by combination of all-trans-retinoic acid and arsenic trioxide. Leukemia Research. 2014;38:977-982

[77] Rogers CS, Yedjou CG, Sutton DJ, Tchounwou PB. Vitamin D3 potentiates the antitumorigenic effects of arsenic trioxide in human leukemia (HL-60) cells. Experimental Hematology \& Oncology. 2014;3:9 
[78] Muto A, Kizaki M, Kawamura C, Matsushita H, Fukuchi Y, Umezawa A, et al. A novel differentiation-inducing therapy for acute promyelocytic leukemia with a combination of arsenic trioxide and GM-CSF. Leukemia. 2001;15:1176-1184

[79] Kumagai T, Shih LY, Hughes SV, Desmond JC, O'Kelly J, Hewison M, et al. 19-Nor1,25(OH)2D2 (a novel, noncalcemic vitamin D analogue), combined with arsenic trioxide, has potent antitumor activity against myeloid leukemia. Cancer Research. 2005;65:2488-2497

[80] Yu Z, Wang R, Xu L, Dong J, Jing Y. N-(beta-Elemene-13-yl)tryptophan methyl ester induces apoptosis in human leukemia cells and synergizes with arsenic trioxide through a hydrogen peroxide dependent pathway. Cancer Letters. 2008;269:165-173

[81] Noh EK, Kim H, Park MJ, Baek JH, Park JH, Cha SJ, et al. Gefitinib enhances arsenic trioxide $\left(\mathrm{AS}_{2} \mathrm{O}_{3}\right)$-induced differentiation of acute promyelocytic leukemia cell line. Leukemia Research. 2010;34:1501-1505

[82] Noguera NI, Pelosi E, Angelini DF, Piredda ML, Guerrera G, Piras E, et al. High-dose ascorbate and arsenic trioxide selectively kill acute myeloid leukemia and acute promyelocytic leukemia blasts in vitro. Oncotarget. 2017;8:32550-32565

[83] Thiede C, Steudel C, Mohr B, Schaich M, Schäkel U, Platzbecker U, et al. Analysis of FLT3-activating mutations in 979 patients with acute myelogenous leukemia: Association with FAB subtypes and identification of subgroups with poor prognosis. Blood. 2002;99:4326-4335

[84] Takahashi S, Harigae H, Yokoyama H, Ishikawa I, Abe S, Imaizumi M, et al. Synergistic effect of arsenic trioxide and flt 3 inhibition on cells with flt 3 internal tandem duplication. International Journal of Hematology. 2006;84:256-261

[85] Wang LN, Tang YL, Zhang YC, Zhang ZH, Liu XJ, Ke ZY, et al. Arsenic trioxide and alltrans-retinoic acid selectively exert synergistic cytotoxicity against FLT3-ITD AML cells via co-inhibition of FLT3 signaling pathways. Leukemia \& Lymphoma. 2017;58:2426-2438

[86] El Hajj H, Dassouki Z, Berthier C, Raffoux E, Ades L, Legrand O, et al. Retinoic acid and arsenic trioxide trigger degradation of mutated NPM1, resulting in apoptosis of AML cells. Blood. 2015;125:3447-3454

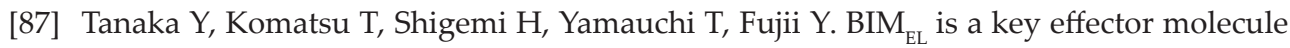
in oxidative stress-mediated apoptosis in acute myeloid leukemia cells when combined with arsenic trioxide and buthionine sulfoximine. BMC Cancer. 2014;14:27

[88] Chen D, Chan R, Waxman S, Jing Y. Buthionine sulfoximine enhancement of arsenic trioxide-induced apoptosis in leukemia and lymphoma cells is mediated via activation of c-Jun NH2-terminal kinase and up-regulation of death receptors. Cancer Research. 2006;66:11416-11123

[89] Emadi A, Sadowska M, Carter-Cooper B, Bhatnagar V, van der Merwe I, et al. Perturbation of cellular oxidative state induced by dichloroacetate and arsenic trioxide for treatment of acute myeloid leukemia. Leukemia Research. 2015;39:719-729 
[90] Chau D, Ng K, Chan TS, Cheng YY, Fong B, Tam S, et al. Azacytidine sensitizes acute myeloid leukemia cells to arsenic trioxide by up-regulating the arsenic transporter aquaglyceroporin 9. Journal of Hematology \& Oncology. 2015;8:46

[91] Dembitz V, Lalic H, Ostojic A, Vrhovac R, Banfic H, Visnjic D. The mechanism of synergistic effects of arsenic trioxide and rapamycin in acute myeloid leukemia cell lines lacking typical $t(15 ; 17)$ translocation. International Journal of Hematology. 2015;102:12-24

[92] Ye Y, Xu X, Zhang M, Qiu D, Bai X, Wang J, et al. Low-dose arsenic trioxide combined with aclacinomycin a synergistically enhances the cytotoxic effect on human acute myelogenous leukemia cell lines by induction of apoptosis. Leukemia \& Lymphoma. 2015;56:3159-3167

[93] Wang R, Liu C, Xia L, Zhao G, Gabrilove J, Waxman S, et al. Ethacrynic acid and a derivative enhance apoptosis in arsenic trioxide-treated myeloid leukemia and lymphoma cells: The role of glutathione S-transferase p1-1. Clinical Cancer Research. 2012;18:6690-6701

[94] Berenson JR, Boccia R, Siegel D, Bozdech M, Bessudo A, Stadtmauer E, et al. Efficacy and safety of melphalan, arsenic trioxide and ascorbic acid combination therapy in patients with relapsed or refractory multiple myeloma: A prospective, multicenter, phase II, single-arm study. British Journal of Haematology. 2006;135:174-183

[95] Grad JM, Bahlis NJ, Reis I, Oshiro MM, Dalton WS, Boise LH. Ascorbic acid enhances arsenic trioxide-induced cytotoxicity in multiple myeloma cells. Blood. 2001;98:805-913

[96] Stewart AK. Novel therapeutics in multiple myeloma. Hematology. 2012;17(Suppl 1): S105-S108

[97] Wen J, Feng Y, Huang W, Chen H, Liao B, Rice L, et al. Enhanced antimyeloma cytotoxicity by the combination of arsenic trioxide and bortezomib is further potentiated by p38 MAPK inhibition. Leukemia Research. 2010;34:85-92

[98] Jian Y, Gao W, Geng C, Zhou H, Leng Y, Li Y, et al. Arsenic trioxide potentiates sensitivity of multiple myeloma cells to lenalidomide by upregulating cereblon expression levels. Oncology Letters. 2017;14:3243-3248

[99] Diaz Z, Colombo M, Mann KK, Su H, Smith KN, Bohle DS, et al. Trolox selectively enhances arsenic-mediated oxidative stress and apoptosis in APL and other malignant cell lines. Blood. 2005;105:1237-1245

[100] Lunghi P, Giuliani N, Mazzera L, Lombardi G, Ricca M, Corradi A, et al. Targeting MEK/MAPK signal transduction module potentiates ATO-induced apoptosis in multiple myeloma cells through multiple signaling pathways. Blood. 2008;112:2450-2462

[101] Liu P, Xu S, Zhang M, Wang WW, Zhang YF, Rehman K, et al. Anticancer activity in human multiple myeloma U266 cells: Synergy between cryptotanshinone and arsenic trioxide. Metallomics. 2013;5:871-878

[102] Shin DS, Kim HN, Shin KD, Yoon YJ, Kim SJ, Han DC, et al. Cryptotanshinone inhibits constitutive signal transducer and activator of transcription 3 function through blocking the dimerization in DU145 prostate cancer cells. Cancer Research. 2009;69:193-202 
[103] Doudican NA, Wen SY, Mazumder A, Orlow SJ. Sulforaphane synergistically enhances the cytotoxicity of arsenic trioxide in multiple myeloma cells via stress-mediated pathways. Oncology Reports. 2012;28:1851-1858

[104] Du Y, Wang K, Fang H, Li J, Xiao D, Zheng P, et al. Coordination of intrinsic, extrinsic, and endoplasmic reticulum-mediated apoptosis by imatinib mesylate combined with arsenic trioxide in chronic myeloid leukemia. Blood. 2006;107:1582-1590

[105] Wang W, Lv FF, Du Y, Li N, Chen Y, Chen L. The effect of nilotinib plus arsenic trioxide on the proliferation and differentiation of primary leukemic cells from patients with chronic myoloid leukemia in blast crisis. Cancer Cell International. 2015;15:10

[106] Xia Y, Fang H, Zhang J, Du Y. Endoplasmic reticulum stress-mediated apoptosis in imatinib-resistant leukemic K562-r cells triggered by AMN107 combined with arsenic trioxide. Experimental Biology and Medicine (Maywood, N.J.). 2013;238:932-942

[107] Li Y, Zhu X, Gu J, Dong D, Yao J, Lin C, et al. Anti-miR-21oligonucleotide sensitizes leukemic K562 cells to arsenic trioxide by inducing apoptosis. Cancer Science. 2010;101:948-954

[108] El Eit RM, Iskandarani AN, Saliba JL, Jabbour MN, Mahfouz RA, Bitar NM, et al. Effective targeting of chronic myeloid leukemia initiating activity with the combination of arsenic trioxide and interferon alpha. International Journal of Cancer. 2014;134:988-996

[109] Bazarbachi A, El-Sabban ME, Nasr R, Quignon F, Awaraji C, Kersual J, et al. Arsenic trioxide and interferon-alpha synergize to induce cell cycle arrest and apoptosis in human T-cell lymphotropic virus type I-transformed cells. Blood. 1999;93:278-283

[110] El-Sabban ME, Nasr R, Dbaibo G, Hermine O, Abboushi N, Quignon F, et al. Arsenicinterferon-alpha-triggered apoptosis in HTLV-I transformed cells is associated with tax down-regulation and reversal of NF-kappa B activation. Blood. 2000;96:2849-2855

[111] Abou-Merhi R, Khoriaty R, Arnoult D, El Hajj H, Dbouk H, Munier S, et al. PS-341 or a combination of arsenic trioxide and interferon-alpha inhibit growth and induce caspase-dependent apoptosis in KSHV/HHV-8-infected primary effusion lymphoma cells. Leukemia. 2007;21:1792-1801

[112] Darwiche N, El-Sabban M, Bazzi R, Nasr R, Al-Hashimi S, Hermine O, et al. Retinoic acid dramatically enhances the arsenic trioxide-induced cell cycle arrest and apoptosis in retinoic acid receptor alpha-positive human T-cell lymphotropic virus type-I-transformed cells. The Hematology Journal. 2001;2:127-135

[113] Bornhauser BC, Bonapace L, Lindholm D, Martinez R, Cario G, Schrappe M, et al. Lowdose arsenic trioxide sensitizes glucocorticoid-resistant acute lymphoblastic leukemia cells to dexamethasone via an Akt-dependent pathway. Blood. 2007;110:2084-2091

[114] Jung HJ, Chen Z, McCarty N. Synergistic anticancer effects of arsenic trioxide with bortezomib in mantle cell lymphoma. American Journal of Hematology. 2012;87:1057-1064

[115] Zhao LL, Liu YF, Peng LJ, Fei AM, Cui W, Miao SC, et al. Arsenic trioxide rewires mantle cell lymphoma response to bortezomib. Cancer Medicine. 2015;4:1754-1766 
[116] Ding X, Chi J, Yang X, Hao J, Liu C, Zhu C, et al. Cucurbitacin B synergistically enhances the apoptosis-inducing effect of arsenic trioxide by inhibiting STAT3 phosphorylation in lymphoma Ramos cells. Leukemia \& Lymphoma. 2017;58:2439-2451

[117] Hassani S, Khaleghian A, Ahmadian S, Alizadeh S, Alimoghaddam K, Ghavamzadeh A, et al. Redistribution of cell cycle by arsenic trioxide is associated with demethylation and expression changes of cell cycle related genes in acute promyelocytic leukemia cell line (NB4). Annals of Hematology. 2018;97:83-93

[118] Ji H, Li Y, Jiang F, Wang X, Zhang J, Shen J, et al. Inhibition of transforming growth factor beta/SMAD signal by MiR-155 is involved in arsenic trioxide-induced anti-angiogenesis in prostate cancer. Cancer Science. 2014;105:1541-1549

[119] Zheng L, Jiang H, Zhang ZW, Wang KN, Wang QF, Li QL, et al. Arsenic trioxide inhibits viability and induces apoptosis through reactivating the Wnt inhibitor secreted frizzled related protein-1 in prostate cancer cells. OncoTargets and Therapy. 2016;9:885-894

[120] Si L, Jiang F, Li Y, Ye X, Mu J, Wang X, et al. Induction of the mesenchymal to epithelial transition by demethylation-activated microRNA-200c is involved in the antimigration/invasion effects of arsenic trioxide on human breast cancer cells. Molecular Carcinogenesis. 2015;54:859-869

[121] Meacham CE, Morrison SJ. Tumour heterogeneity and cancer cell plasticity. Nature. 2013;501:328-337

[122] Ding L, Ley TJ, Larson DE, Miller CA, Koboldt DC, Welch JS, et al. Clonal evolution in relapsed acute myeloid leukaemia revealed by whole-genome sequencing. Nature. 2012;481:506-510

[123] Lohr JG, Stojanov P, Carter SL, Cruz-Gordillo P, Lawrence MS, Auclair D, et al. Widespread genetic heterogeneity in multiple myeloma: Implications for targeted therapy. Cancer Cell. 2014;25:91-101 